\title{
ASSESSMENT OF DAMAGE AND MITIGATION STRATEGIES FOR THE MISQUAMICUT, RI COASTAL COMMUNITY FROM A 100 YEAR STORM EVENT AND SEA LEVEL RISE
}

\author{
Jamie Schicho, Christopher Bianchi, Lauren Folkert, Julie-Ann Knight, Hannah Madison, Mathew Maroukis, Brendan Quinn, \\ Michael White, Malcolm Spaulding, Christopher Baxter, University of Rhode Island (jamie schicho@my.uri.edu, \\ cbianchi94@my.uri.edu, folkertl@my.uri.edu, jmknight@my.uri.edu, hannah madison@my.uri.edu, mmaroukis@my.uri.edu, \\ brendan quinn@my.uri.edu, whitey0408@my.uri.edu, spaulding@uri.edu, cbaxter@uri.edu) \\ Craig Swanson, Swanson Environmental Associates LLC, craig.swanson@swansonenvironmental.com
}

\begin{abstract}
Misquamicut is a coastal community located in Westerly, Rhode Island with a high density of structures that is at risk from inundation, wave, and wind damage from large storm events. The area has suffered significant damage from storms in the past such as the Hurricane of 1938 , Hurricane Carol in 1954, and most recently, Superstorm Sandy in 2012. This area is also highly susceptible to sea level rise (SLR), which is predicted to be as high as 7 feet by the year 2100 (NOAA, 2017). A tool called the Coastal Environmental Risk Index (CERI) was used to estimate damage to structures located in Misquamicut due to a 100 year storm event with and without 7 feet of sea level rise. Using CERI, four mitigation strategies were evaluated to improve resiliency of the community: basement window plugs, dune restoration and reinforcement, a tide gate, and elevation of structures.
\end{abstract}

\section{METHODOLOGY}

This study was accomplished using a Geographical Information Systems (GIS) tool called the Coastal Environmental Risk Index (CERI; Spaulding et al. 2016) (Figure 1).

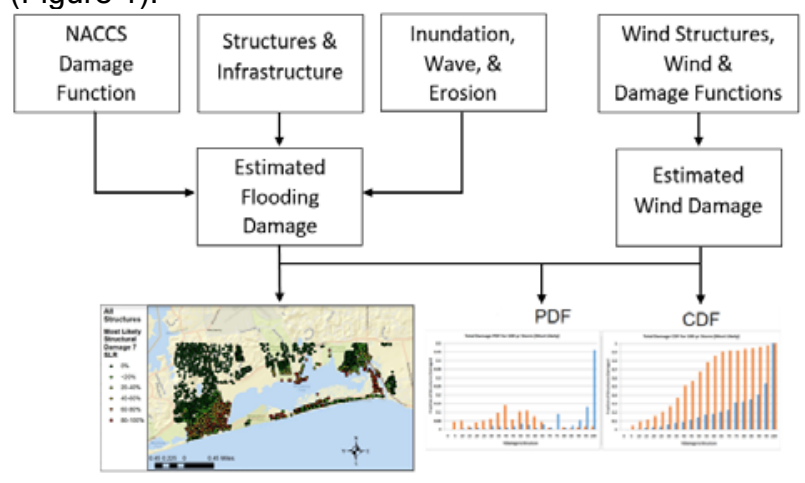

Figure 1 - Flow chart for the Coastal Environmental Risk Index (CERI)

Inputs into CERI include detailed information about each structure from an E911 database, inundation levels taken from STORMTOOLS (www.beachsamp.org), and wave heights estimated by the Steady State Spectral Wave Model (STWAVE). These values were used to estimate percent damage to individual structures using damage functions created by the United States Army Corps of Engineers (USACE) during the North Atlantic Coast Comprehensive Study (NACCS). A new wind protocol was added to estimate wind damage using damage functions based on structural characteristics taken from the FEMA Hazus Hurricane Model. Westerly public records were used to obtain the structural data required by the Wind Protocol.

\section{TOTAL DAMAGE AND MITIGATION STRATEGIES}

Using CERI, the combined damage from inundation, wave action, erosion, and wind was estimated for a 100 year storm event with and without 7 feet of sea level rise (e.g. Figure 2). Four mitigation strategies were evaluated to reduce damage and improve resiliency of the community: basement window plugs, dune restoration and reinforcement, a tide gate, and elevation of structures.

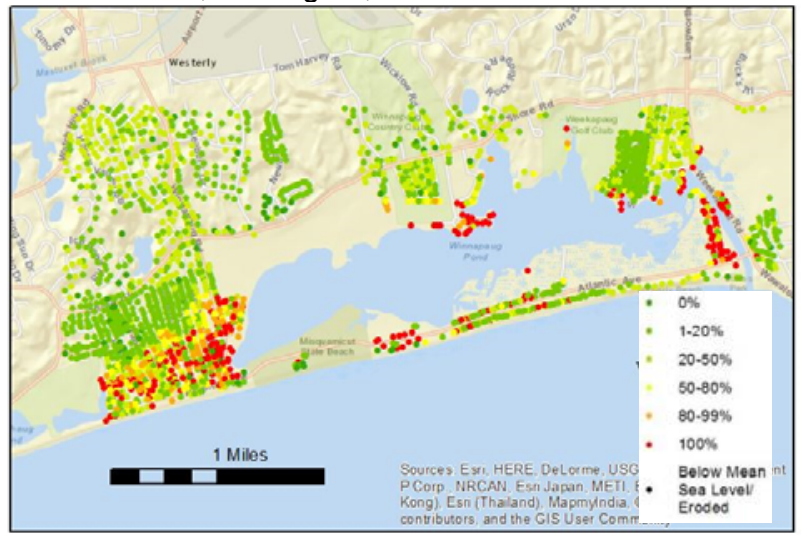

Figure 2 - Total estimated damage to each structure in the study area from a $100 \mathrm{yr}$ storm with $0 \mathrm{ft}$ of SLR

\section{RESULTS AND CONCLUSION}

For the approximately 2000 homes in Misquamicut, RI, it is estimated that a $100 \mathrm{yr}$. storm with no SLR would damage 342 houses $>50 \%$, forcing them to be rebuilt to new building standards. Including SLR and predicted erosion for the year 2100, the number of structures needed to be rebuilt increased to 899. To mitigate against these damages, plugging of basement windows is the cheapest strategy but is only relevant for approximately 200 structures and resulted in relatively minor reductions in damage. Dune restoration is expensive but benefits large parts of the community. Tide gates protect many structures from nuisance storms but will fail in anything larger than a 25 year storm. Elevation of structures yields the greatest reduction of damage to the effects of storms and sea level rise. Most importantly, this study illustrates the benefits of using an objective, quantitative tool like $\mathrm{CERI}$ to assess the risk that structures and infrastructure face from storm events and sea level rise.

\section{REFERENCES}

NOAA Sea Level Rise Viewer (https://coast.noaa.gov/ digitalcoast/tools/slr; accessed Aug. 31, 2017).

Spaulding, Grilli, Damon, Crean, Fugate, Oakley, and Stempel (2016): STORMTOOLS: Coastal Environmental Risk Index, J. of Mar. Sci. and Eng.MDPI, vol. 4, 54 